\title{
DIFFUSION INNOVATION
}

\author{
Saša Stepanov ${ }^{1}$ \\ Todor Petković ${ }^{2}$ \\ Nemanja Stepanov ${ }^{3}$
}

DOI: https://doi.org/10.31410/ERAZ.2019.353

\begin{abstract}
Innovations, as a result of innovation and creativity, are characteristic of all areas of human activity. The concepts of innovation and innovation are primarily related to the economic sphere and business of business entities. Innovation must have practical application, to benefit as an innovator (material and moral satisfaction), as well as to recipients of these innovations. A particularly important area in the transfer of innovations is the legal protection of intellectual property - how innovators protect their ideas from unauthorized use or misuse of innovations.
\end{abstract}

Keywords: innovation, creativity, business entities, diffusion of innovation, protection of intellectual property.

\section{INTRODUCTION}

Tn the literature can be found many definitions of innovation, innovation, and the like terms.

1 According to one definition, the innovations are the ,'process whereby the idea of being transformed into a new / improved products, services or processes in order to improve its own, and differentiation of the competition on the market" [8]. There is also a wider and shorter the definition of innovation [10]. According to a broader definition, innovation is' renewal and expansion of range of products, services and their market; the establishment of new methods of production, supply and distribution; the introduction of changes in management, work organization, working conditions and skills of the workforce ,. According to another shorter and consistent definition, it is a , transformation of ideas into new or improving technological processes or products; new organizational system or a new approach to the services'. According to Peter Drucker, innovation is', a specific tool of entrepreneurs, the means by which they exploit change as an opportunity for different products and different services' [2, p. 101].

Innovations relating to all spheres of human activity and therefore can talk about social innovations, technical and technological innovation and business innovation. The Innovation in business, they can equally occur in the manufacturing or service industries, and - tourism, trade, banking, insurance and the like. The public innovation very often associated with entrepreneurship and highlights the temporal aspect: that innovation should appear at the right time and to be the first or second with innovation. As sources of innovation, Drucker lists seven factors are grouped into two groups - internal (from the point of undertaking) and external. The internal sources include: unexpected inconsistency, and the needs of the sudden change in the economic structure. As external sources said demographic trends and new scientific findings [4, p. 7-8].

MEF, Faculty of Applied Menagement, Economy and Finance, Jevrejska 24/1, Belgrade, Serbia

VPSSS Cacak, City park 2, Zemun, Belgrade, Serbia

Faculty of Political Science, Jove Ilića 165, Belgrade, Serbia 
When it comes to the form of innovation, we can talk about a new product or service and new organizational process. Innovation can only apply to one or more companies in one country but also has a universal character. A particularly important element of any innovation is the convenience and the opportunity to be applicable in practice or in an economically justifiable ground.

A possible application of an innovation in economic fundamentals justified if not the most important, then certainly one of the most important preconditions for what is the theme of this work - the diffusion and dissemination of innovations. Without fulfilling this condition has no social or economic base for the sale and purchase of an innovation, no matter how much she represented novelty in its field.

\section{ELEMENTS OF THE DIFFUSION INNOVATION PROCESS}

The diffusion (spreading) innovation is considering a whole set of important issues that determine whether an innovation will remain in a narrow circle of its creator or to ,see the light of day', and allow the benefit of its application to a wide range of people. The most important issues in this area are as under what conditions and at what speed the spread of innovation, legal aspect - protection of intellectual property and the like. It is usually defined as a process of diffusion of innovations to a larger number of different users, with its use in certain variations, modifications, (depending on the specific requirements and needs of the recipients), including improvements in relation to the original innovation. Diffusion of innovation takes place in two main directions so we can talk about horizontal and vertical expansion. Horizontal diffusion means expansion in spatial terms - between certain geographic areas, regions and countries. The vertical diffusion means expansion in one industry, social services or scientific field.

\subsection{Innovation as an intellectual property}

Every innovation is the result of human activity and intellectual effort and as such must be the object of protection of the rights and interests of innovators. In practice, there are different forms and degrees of protection of these rights.

Patent [3, 2010] is ,exclusive right recognized for an invention which is a product or process that provides a new way of doing something or offering a new technical solution to the problem. The exclusive right implies the right to prevent third parties from commercially exploiting a patented invention without the permission of the patent owner ,(Intellectual Property Office of the Republic of Serbia, 2010, 2).

Patents and small patents are recognized in our country by the Intellectual Property Office of the Republic of Serbia [11]. This protection has a limited duration of time - usually 20 years, while for a small patent, this period is 10 years, counting from the date of filing the patent application. In addition to time, the patent has a territorial - geographical restriction and refers to the State in which that patent is recognized. The patent application and the recognized patent are made available to the public by publishing in the Intellectual Property Bulletin of the Republic of Serbia.

Except in its own country, the patent can be protected also abroad. This is a prerequisite for spreading innovation beyond the boundaries of its own country - that a business entity licenses its innovations, to develop other forms of business cooperation and to be present in foreign mar- 
kets. Innovators have three basic ways of protecting inventions abroad: (1) national, (2) regional (through the European Patent Organization) and (3) international.

The patent is just one of the prerequisites for innovation to succeed in the market and it is not a guarantee that innovation will be commercialized to the expected extent.

The stamp [12] is a legally protected sign by which a legal and natural person identifies its products and services in the traffic with the aim of distinguishing them from similar or identical goods and services offered on the market by other legal and natural persons. Using the terminology of marketing, it can be said that the use of the trademark in the function of differentiating the specific manufacturer, service provider, their products and services in relation to the competition.

Individual, collective and quality guarantees should be distinguished. An individual trademark is a legal trademark used by the holder or the owner of the trademark. In the role of the holder of this type of trademark, a legal or natural person is registered, on whose behalf the trademark is registered at the Intellectual Property Office. Unlike him, the collective trademark can be used not only by trademark holders, but also by other persons authorized by the trademark holder. When more than one business entity uses a trademark under the control of a trademark holder to serve as a guarantee of quality, geographical origin, production method or other common features, then it is a quality mark.

The stamp lasts 10 years and after the expiration of that period, its validity can be extended also for the same period of time, and this unlimited number of times. Otherwise, the issue of trademarks is regulated by the special Law on Trademarks [6, 1041/2009 and 10/2013], as well as numerous international agreements.

Industrial design [12] in order to be protected must be: (1) new (if it is not known that the identical design existed before) and (2) has an individual character (in the event that the impression left to the informed user differs from of the overall impression left to that user by some other earlier industrial design).

It is defined as ,a three-dimensional or two-dimensional appearance of the entire product, or its part, which is determined by its visual characteristics, special lines, colors, shape, texture and / or materials from which the product is made, or which it is decorated, and its combination ,' [12].

An important feature of this kind of protection of intellectual property is that it must be suitable for industrial applications-that it can be manufactured in an industrial or craft manner. Otherwise, this is an ,artistic" achievement that can be protected in a different way-through the protection of copyrights.[13]

There are many reasons why business entities decide to apply this form of protection for their innovations and products. The geographical indication has a significant role not only in promotional but also in overall activities, with the aim of suggesting to customers the quality of products (as a rule of high and highest quality), differentiation from the competition and market recognition [14].

The topography of semiconductor products [15] protects innovation in this field since mid2013 by the Law on the Protection of Semiconductor Products. It is also a novelty in relation to the previous Law on the Protection of Semiconductor Vehicles. Considering that information 
technology is one of the fastest growing activities with an extremely high number of innovations, the need has been shown to improve the existing legislation (which was in force until June 201) and to align it with international regulations in this field.

The topography of semiconductor components is in fact a three-dimensional layout of layers of conductive, insulating and semiconductor materials intended for the performance of a certain electronic function. Protection covers only a topography as a 3D layout of the above layers, and not a concept, process, system, or production technique.

License: Unlike a patent that defines the basic principles of functioning of one invention, the license implies supporting documentation (constructive, workshop, instructions ...) which is necessary for starting the production process. The license agreement regulates a number of issues such as the definition of the licensee and licensee, the subject of the license, the fee that the licensee must pay to the licensee (amount, payment dynamics, etc.), the period of validity of the license, the scope and content of the necessary supporting documentation. An important item in each license agreement is the prohibition that the licensee independently disposes of the received supporting documentation, and in particular its assignment to third parties without the approval of the licensee.

Know-How is probably the most complete way to transfer an innovation. It was created in the second half of the last century, first in the most developed industrial countries - the United States and England. This implies the transfer of expertise and experience on the technology and production process of a particular product [9].

In the literature, the difference between commercial and technical knowledge is transmitted. Technical know-how consists of production methods and procedures that make business secrets (standards, recipes, specifications) while commercial know-how make knowledge and business methods (sales organization, service realization, etc.).

\subsection{Factors that influence the process of diffusion of innovations}

There are many factors that depend on whether an innovation will be applied in practice. The degree and speed of the expansion of innovation are significantly influenced by the following factors: (1) global (in accordance with the processes of globalization and internationalization, politics, technology and the like, with the significant role of international companies), (2) economically (through the transfer of innovation, competitive and long-term sustainable position in a particular market), (3) financially (considering the availability of capital both for investment in research and development that will result in innovations, and for the purchase of innovations through licenses, patents and other forms of intellectual property under protection) (4) resources (a number of natural and other resources, counting the geographical position or proximity of the market that is large enough or economically strong to accept innovation in the form of new products and services) [2, p. 115].

Numerous and diverse factors of the impact on the diffusion of innovation can be classified into two groups:

1. Economic factors. In the modern economy, every business activity should be economically justified. This is especially true for innovations given that they are preceded by significant engagement of human and financial resources. Research costs, regardless of whether they are from own funds or bank loans, must be reimbursed. This will only be achieved if innovation can be marketed at certain prices. 
- Diffusion time, one innovation will depend on how much investment in innovation is economically viable and cost-effective. When innovation becomes economically justified and as such begins to be used in practice, it will be accepted by other business entities who do not want to lag behind the innovator.

- Price of production factor (labor, work, and labor) are also an important input element for the expansion of an innovation. Each innovation should provide optimal costs and a combination of production factors in order to achieve the appropriate rates of basic economic indicators (productivity, cost-effectiveness and profitability rates).

- Life expectancy of fixed assets also has a significant impact on the spread of innovation. The longer this is, the innovation will be more rapidly and more widely spread.

2. Socio-psychological factors. A favorable social and innovative climate, institutional support for innovative processes, encouraging creativity, a desire for social satisfaction and prestige are positive for the expansion of innovation. On the other hand, lack of interest, insufficient professional and practical knowledge, as well as the absence of stimulative measures at the micro and macro level for innovation, will negatively affect the innovative processes and, consequently, their spread.

Numerous socio-psychological factors are best systematized as barriers and limitations on the macro and micro level [5, p. 13-18]. Prerequisites at macro level: (1) innovative climate and traditions in society, (2) legal security in the form of legal protection of innovations, intellectual property, patents, (3) institutional support at state and local level for the development of entrepreneurship, innovative processes and transfer of innovations in country and abroad.

In the framework of support from the competent institutions of the Republic of Serbia, it is necessary to mention those activities that are specifically aimed at encouraging the innovation of domestic companies and the spread of innovative products to foreign markets. One of them is the Competitiveness and Innovation framework Program (CIP). It started in 2007 and lasted until 2012. At the end of 2008, Serbia entered into its sub-program „The Entrepreneurship and Innovation Program" (EIP) as a full member [5, p. 106]. Through the EIP, the SME sector has been given easier access to funding sources, and innovation is particularly encouraged with an emphasis on eco-innovation.

Preconditions at the micro level: (1) fostering innovative processes in businesses, in that innovation often occurs in enterprises, (2) motivation of employees and management to permanently innovate not only products and services, but also production processes and organization of all business, (3) stimulating and rewarding employees and management (innovators in companies need to receive fair financial incentives, to know that they can count on improvement and better workplace and other types of financial and non-financial incentives due to their innovation and creativity), (4) acceptance and understanding of changes in the environment (this is certainly one of the most important factors contributing to the expansion of innovation), (5) willingness to cooperate with innovators, scientific institutions, development centers and financial institutions. Innovation often requires the engagement of human and financial resources beyond the real possibilities of a business entity. Carriers of innovative processes must be aware of certain obstacles that can significantly impede the emergence of innovations and their dissemination to stakeholders.

Barriers to disseminating innovation at the macro level: (1) insufficient and inadequate protection of intellectual property, (2) administrative barriers at the state level, (3) inadequate institutional support for innovative processes, (4) non-imitative customs and tax policy. 
Obstacles to the spread of innovation at the level of business entities: (1) unwillingness to accept newspaper in business (this is one of the biggest obstacles to the spread of innovation. It happens that owners and employees simply do not want to accept the inevitable changes in the production program and organizational processes) (2) lack of financial resources for the development of innovations and their purchase (although at first glance it acts as an insurmountable obstacle for many economic entities, there is a solution for such situations). In the first place, it refers to numerous institutions and measures of state and local authorities that stimulate application of innovations).

\subsection{Phases of diffusion of innovation}

The expansion of innovation, that is, the period from creating innovation to its application in practice by different subjects is a process that requires a certain period of time and is carried out at certain stages.

According to Roger (Everett M. Rogers), an American theoretician and professor deemed to be a pioneer in theoretical consideration of the diffusion of innovations and the author of the often-used term early adopter [10] (the term that denotes early adopters or early followers-subjects that accept innovations immediately after the innovator).

There are also different views of the phase implementation of the expansion of innovation. According to such an understanding, the diffusion of innovation is carried out through three phases. In the initial phase, stakeholders are introduced to innovation. In the next phase, the adoption of innovation follows, resulting in the final phase - the practical application of innovation.

\subsection{Specificity of the diffusion of innovation in the sector SME}

Since micro, small and medium enterprises account for around $99 \%$ of the total number of companies in the world and in our country, it is necessary to point out some of the specifics that are present in the process of diffusion of innovations within these companies.

Innovation is the main source of vitality for entrepreneurs, small and medium-sized enterprises. They are also the factor of their survival on the market in conditions of pronounced competition.

Small and medium-sized enterprises are the bearers of innovative processes in branches and emerging industries, unlike mature branches where, in terms of innovation, large enterprises and international corporations are of considerable advantage. The main innovative advantage of the $S M E$ sector is the speed - the ability to react very quickly to changes in the environment, which are often sudden. On the other hand, the greatest constraints on even greater innovation in this sector are the lack of experts and financial resources for a costly research.

Taking into account all the advantages and disadvantages of this sector in terms of innovation, special attention must be paid to the attitude of employees in introducing innovations. Owners and management in the micro, small and medium-sized enterprises and entrepreneurs must be aware of the fact that employees react differently to the innovations introduced and that open or covert resistance to change is possible. 


\subsection{Economic justification for the introduction of innovations}

Any innovation can be viewed from a purely technical point of view, of social importance and economic justification. From the point of view of economic subjects, the most important is the economic aspect of innovation, that is, it is economically justified to expand the innovation. It should be emphasized that there are numerous innovations which from purely economic aspect are not justified, but therefore have a wider social significance. It is about numerous innovations related to environmental protection, health care of the population, education, defense capability of the state, etc.

The innovation economy focuses on maximizing profits. It is necessary to take into account other important indicators: the impact on the ecological environment, working conditions and safety at work, the quality of products, the time needed for the adoption of innovation, the state of competition, the ability to conquer new markets, Moreover, if innovation is economically justified for a single undertaking, it does not necessarily mean that there is an economic justification for its introduction to another company, business branch or market.

\subsection{Advantages and disadvantages of the process of spreading innovations}

Every social, economic, scientific and political activity must be viewed from different aspects, that is, to recognize the advantages, but at the same time, the disadvantages that each process and every phenomenon has.

The benefits of spreading innovation are more than familiar. They also enable those companies and societies in general where innovative processes did not sufficiently come to life, to get through the necessary news.

Also, if the innovation is accepted by a sufficient number of stakeholders and if the goals of introducing innovations are met, it is said that the effects of spreading innovation are positive.

Deficiency the process of spreading innovation leads to numerous negative economic and social effects.

In particular, the negative side should be emphasized and the ,abuse” of innovations in the socalled ,psychological obsolescence” of the product. It is an unnecessary shortening of the life span of individual products through the introduction of unreasonable changes in products, in order to distinguish one product at any cost from the competition. This should also be added to the practice that new products often involve new unrealistically high prices, which means that consumers are expensive to pay for unnecessary innovations.

Negative effects of the expansion of innovation can be recognized in practice that some entities prefer to buy ready-made innovations instead of developing innovative processes themselves. In this way they become dependent on innovators, often in the form of international companies.

\subsection{Multinational Models of Innovation Spread}

In professional literature in this field, four models of the expansion of innovations are commonly mentioned [1, 2005, p. 671-683]. 
Aggregate models observe the diffusion of innovations at the level of the whole population or groups of possible users, assuming that such groups are homogeneous.

Models of repeated purchase aim to explain the process of expanding innovations related to consumer product innovation. Models on the micro level observe individuals as potential beneficiaries (innovators) of innovation. Bearing in mind that modern business conditions are characterized by globalization and a significant volume of international trade, the diffusion of innovation must be seen in these frameworks. In practice, this means that it is not possible to observe the process of disseminating innovation closely - only within the framework of one state, but all aspects of transfer of innovation in the nearer and wider environment of the country from which the innovation comes in must be taken into account. That is why multinational models of diffusion of innovations are being developed.

\subsubsection{Boss's model of diffusion of innovation}

Basov [7] model (Bass Model or Bass Diffusion Model) refers to the theory of determining the initial - initial purchase of new durable products. It lists the growth model according to which the sale goes up the line to the maximum point, after which the sale decreases. He was the first to give a model of the expansion of innovations according to the principle of the model of the spread of the epidemic $[1,2005$, p. 672]. Innovation, according to this model, is spreading like an epidemic, those subjects that have not yet adopted innovations are ,infected" with those who have already adopted innovations. By the flow of time, innovation will be adopted if not from all then by most of the entities.

By the time the innovations were adopted, Bas distinguishes two types of subjects. In the first place are innovators - individual entities that adopt innovations independently of other subjects while in the second group - imitators all other subjects.

Bases' model of diffusion of innovation is the basis for a number of models of expansion of innovations in international economic relations. Otherwise, Bas, besides Rogers, is the pioneer in the research of innovation in the field of marketing [1, 2005, p. 673].

\subsubsection{Specificity of the process of diffusion of innovations at the international level}

The focus on foreign markets, the need for growth through appearances in foreign markets and the existence of international companies imposes the need for a planned approach to diffusion of innovations in foreign markets. That is why models of diffusion of innovations are needed in order to accelerate the sales and marketing efforts of business entities in the performance of one or more foreign markets.

There are two approaches to consider the spread of innovations in international markets. The first approach is based on researching the differences between processes in the two countries in terms of linking these differences and specificities with social and cultural differences. The expansion of innovation is considered separately for each country, after which the obtained results are compared and specificities are determined. The second approach has a basis in considering the interaction between the process of spreading innovation in two countries. The interactions between the observed countries are approached by two methods: (1) the influence of the country where innovation is first introduced to another country, and (2) the learning effect. This effect is 
influenced by the specificities of a country that respects economic and cultural similarities and time between the introduction of products into these two countries [1, 2005, p. 675].

Model Gatignon, Eliashberg, Robertson is one of the pioneering works dealing with the differences in the spread of innovation in different countries. This model, based on the Basa model, shows the connection between cosmopolitanism, mobility and the participation of the female population in the total labor force from one and the spread of innovation on the other. Their research suggests that a higher level of cosmopolitanism is associated with a greater tendency to innovate, while a higher level of mobility is associated with a larger immigration pattern. The influence of women depends on their role in the purchasing decision-making process $[1,2005,675]$.

Model Parker, Dekimpex, Sarvary estimates the parameters taking into account the differences between the cultures of different countries. Their research is based on the diffusion of innovations in over 180 countries across six continents. Otherwise, the study was done for the needs of the mobile phone industry and shows that ethical heterogeneity has a negative, and income per capita has a positive impact on the spread of innovation. The disadvantage of this model is that it only applies to the mobile phone industry, but not to some other industry.

Model Tellefsen and Tekada deals with the influence of the availability of mass media (television, radio, newspapers) in the process of diffusion of innovations in different countries. Their study shows that the prevalence of television as a medium largely affects the coefficient of external influence. Also, they found a negative relationship between newspapers and the coefficient of internal influence. The limitations of this model lie in the fact that the authors measured the impact of mass media on the sale of new products, while not taking into account a number of cultural, political, social and other specific countries.

\subsubsection{Research into the interaction between the processes of spreading innovation in more different countries}

The expansion of innovations in international economic relations can also be viewed through the exploration of interdependence among the processes of expansion of innovations that take place in different markets $[1,2005$, p. 673-682]. In this way, one phenomenon, in our case, the expansion of innovation, is seen wider and more complete. This is because information holders in one country today have information (primarily thanks to the internet, raising awareness about consumer rights and a significant impact on consumer movements) about products, their prices, quality and sales conditions in some other countries.

The impact of the cultural context and the time of introducing innovation in the two countries to the process of disseminating innovation is the subject of research by the expert team, Hirokaz Takada, Dipak Jain. They conclude that the diffusion rate of innovation is higher in countries with higher education cultural context i.e. which have a higher coefficient of imitation and in which the importance of mutual communication is attached. As regards of the time aspect, the opinions are that innovations are more quickly adopted in the country where the product was subsequently introduced.

Unlike Takada and Jaina, another group of authors in their research did not establish a positive relationship between the time lag of introducing innovation and the rate of adoption. Kristiaan Helsen, Kamel Jediidi, Wayne DeSabro have explored to what extent countries with similar 
macroeconomic variables have the same or similar models of diffusion of innovation. They have established that segments of countries based on expansion patterns do not correspond to traditional segments according to macroeconomic indicators, but rather depend on the product itself.

Kalish, Mahajan, Muller deal with the influence of the first country to explain the choices between the water strategy and the shower strategy when entering the foreign market.

Waterfall strategy means that the economic entity has chosen to gradually enter the foreign market. The company first sells its product or products on the domestic market, then to the developed foreign markets and later to the less developed markets and emerging markets. Unlike this gradual conquest of the market, the strategy of the shower implies that all markets are simultaneously,' attacked ,'.

Impact of the first country shows the effects to which consumers are exposed in countries where innovations are introduced later. Namely, consumers in such countries have the ability to monitor what is happening with innovations in the initial market and get to know it before this innovation appears on their (home) market. In this way, the risk of first and early purchase is considerably reduced, which certainly reduces the period of adoption and expansion of innovation.

Ganesh, Kumar also dealt with the influence of the country of origin of innovation (the leader country) on a land that later accepts innovation and introduces professional literature learning effect. They consider that the success of a product in one country reduces the risk of its introduction in a country that later introduces it. The rapid expansion of innovation in a country that later introduces it can also be explained by the following: the manufacturer has enough time to improve its product and marketing performances and, therefore, better position itself in the awareness of consumers in such markets.

Sundqvist, Frank, Puumalainen analyze the cultural effects, the effects of time and the effects of the earth. They think that the effect of time has the greatest impact on the expansion of innovation by which innovation is expanding faster in those countries where innovation was introduced later.

The effect of culture it works in two ways. The year of adoption depends on the cultural diversity in relation to the country of the source of innovation, and beyond that, the cultures that avoid uncertainty are more focused on imitation.

Respecting the results and significance of these studies, some common characteristics that limit their application in underdeveloped countries must be highlighted. It is the following: (1) in previous studies, the emphasis is on researching the spread of innovation in highly developed countries (it is clear that there are significant differences between developed and underdeveloped countries and that the results of such studies can hardly be applied to underdeveloped countries), (2) these studies, as a rule, relate to innovations in the field of durable consumer goods and products produced as a result of high technology, (3) studies presuppose an open economy, or the country's involvement in international economic flows, (4) studies do not explore the impact of different restrictions on international trade in the form of non-tariff barriers, import quotas, licenses and the like.

Models of the expansion of innovations in the international market have practical application in real business conditions when it comes to choosing a strategy for entering a selected market, 
choosing a market (one country or group of countries) and determining the time to enter the foreign market. Also, the laws that many researchers have found to be valid for one innovation group does not mean that they will automatically apply to some other innovation groups in these same markets. All this points to the importance of knowing the essence of the model, its advantages and disadvantages, as well as the numerous specificities of the market and innovation, with the aim of getting the most accurate estimates.

\section{CONCLUSION}

Innovations are undoubtedly one of the most important factors of survival in the market and the competitive advantages of each undertaking. Innovation and innovation as a result of human creativity can be viewed from different aspects of which the diffusion of innovation is among the most important.

Innovation not only refers to products (completely new or to some extent innovated existing ones), but also to new organizational models, new production processes and methods, and the like. Innovations include new markets, more precisely conquest and entry into regions (regions, countries or groups of related countries), where one business entity has not yet achieved business activity by then. These include the so-called. the „new combination” of existing material and human resources.

The possibility of practical implementation of an innovation on an economically justified basis is, if not the most important, then surely one of the most important assumptions for what is the subject of this paper - diffusion, i.e. expansion of innovations.

Without the fulfillment of this condition, there is no social or economic basis for the sale or purchase of an innovation, regardless of the amount of news that it represented in its field. In order for one innovation to come to life in practice, it must have practical value that is, to satisfy some human need, but at the same time to enable its creator and user a certain economic and social benefit. The expansion of innovation must also have external support. This means that legal security must be provided to the bearers of innovation through various forms of intellectual property protection - patents, licenses, trademarks, industrial design, protection of the geographical origin of a particular product, and more recently through the topography of semiconductor products.

In the professional literature, the past decade has seen an interest in finding optimal models of diffusion of innovations with a special focus on placing innovations on the international market. Depending on the author's understanding and the results of numerous studies, the emphasis is on the quantitative (Bas) or qualitative or psycho-sociological aspect of the expansion of innovation (Rogers); the consideration of the impact of the country of origin of innovation on the countries adopting innovation, the time period necessary to pass from the onset of innovation to its acceptance; cultural, economic and other differences between the countries of origin of innovation and the countries of the adopters of innovations; the impact of mass media and marketing mix on the speed and scope of the expansion of innovation; the influence of the image that has the country of origin of innovation, and the company on potential innovators of innovations, etc. 


\section{REFERENCES}

[1] Božić, Lj. (2005): Multinational Innovation Spreadsheets, Economic Review No. 56/9.

[2] Milošević, M., (2013): Entrepreneurship, Higher Business School of Expert Studies, Čačak, Belgrade.

[3] Patent - How to protect intellectual property? (2010), Educational Information Center of the Intellectual Property Office of the Republic of Serbia, Belgrade.

[4] Stojanović Ž., (2009): Accelerating Innovation, Proceedings of the Faculty of Technology in Leskovac, University of Niš - issue no. 17, Leskovac.

[5] Velimirović, D., Stojanović, R., (2012): Management of small and medium enterprises, High Business School of Vocational Studies „Čačak”, Beograd.

[6] Patent Law, Official Gazette of the Republic of Serbia 99/2011; Law on Trademarks, Official Gazette of the Republic of Serbia 1041/2009 and 10/2013.

[7] www.en.wikipedia.org/wiki/Bass_diffusion_model (access date: April 27, 2019).

[8] www.preduzetnickiservis.rs/sr/novacije-i-inovacioni-potencijali/inovacije (date of access: April 12, 2019).

[9] www.franchising.rs/recnik/know-how/4 Definition of the International Chamber of Commerce in Paris (date of access: April 19, 2019).

[10] www.preduzetnickiservis.rs/ (date of access: April 12, 2019).

[11] www.zis.gov.rs/prava-is/patents/najcesca-pitanja.2.htm (date of access: April 16, 2019).

[12] www.zis.gov.rs/prava-is/zigovi/najcesca-panja.10.html (date of access: April 16, 2019).

[13] www.zis.gov.rs/prava-is/oznake-geografskog-porekla/najcesca-pitanja (access date: April 19, 2019).

[14] www.zis.gov.rs/prava-is/oznake-geografskog-porekla/najcesca-pitanja.26.html (access date: April 19, 2019).

[15] www.zis.gov.rs/prava-isografije-poluprovodnickih-proizvoda (access date: April 19, 2019). 